\title{
Artificial urinary sphincters for male stress urinary incontinence: current perspectives
}

This article was published in the following Dove Press journal:

Medical Devices: Evidence and Research

4 July 2016

Number of times this article has been viewed

\section{Billy H Cordon' \\ Nirmish Singla' \\ Ajay K Singla ${ }^{2}$}

'Department of Urology, University of Texas Southwestern Medical Center, Dallas, TX, 'Department of Urology, University of Toledo College of Medicine, Toledo, OH, USA
Correspondence: Ajay K Singla

Department of Urology, University of

Toledo Medical Center, 3000 Arlington

Avenue, MS 109I, Toledo, OH 436I4,

USA

Tel + I 4193833582

Fax + I 4193833785

Email ajay.singla@utoledo.edu
Abstract: The artificial urinary sphincter (AUS), which has evolved over many years, has become a safe and reliable treatment for stress urinary incontinence and is currently the gold standard. After 4 decades of existence, there is substantial experience with the AUS. Today AUS is most commonly placed for postprostatectomy stress urinary incontinence. Only a small proportion of urologists routinely place AUS. In a survey in 2005 , only $4 \%$ of urologists were considered high-volume AUS implanters, performing $>20$ per year. Globally, $\sim 11,500$ AUSs are placed annually. Over 400 articles have been published regarding the outcomes of AUS, with a wide variance in success rates ranging from $61 \%$ to $100 \%$. Generally speaking, the AUS has good long-term outcomes, with social continence rates of $\sim 79 \%$ and high patient satisfaction usually between $80 \%$ and $90 \%$. Despite good outcomes, a substantial proportion of patients, generally $\sim 25 \%$, will require revision surgery, with the rate of revision increasing with time. Complications requiring revision include infection, urethral atrophy, erosion, and mechanical failure. Most infections are gram-positive skin flora. Urethral atrophy and erosion lie on a spectrum resulting from the same problem, constant urethral compression. However, these two complications are managed differently. Mechanical failure is usually a late complication occurring on average later than infection, atrophy, or erosions. Various techniques may be used during revisions, including cuff relocation, downsizing, transcorporal cuff placement, or tandem cuff placement. Patient satisfaction does not appear to be affected by the need for revision as long as continence is restored. Additionally, AUS following prior sling surgery has comparable outcomes to primary AUS placement. Several new inventions are on the horizon, although none have been approved for use in the US at this point.

Keywords: artificial urinary sphincter, stress urinary incontinence, post prostatectomy incontinence, prostheses and implants, review

\section{Introduction}

Urinary incontinence is a significant quality of life issue affecting a large proportion of the population. ${ }^{1}$ It is estimated that $\sim 22.6$ million men are affected by urinary incontinence and 8.2 million have moderate to severe urinary incontinence. ${ }^{2}$ Pure stress urinary incontinence (SUI) accounts for only a subset (12.5\%) of these patients, yet it remains a substantial and growing problem, especially in the postprostatectomy setting. The artificial urinary sphincter (AUS), which has evolved over many years, has become a safe and reliable treatment for SUI and is currently the gold standard. The first description of an AUS dates back to $1947^{3}$; however, the modern era of sphincters began in 1983 with the release of the AMS 800 (American Medical Systems, Minnetonka, MN, USA; Figure 1). ${ }^{4,5}$ The AUS is composed of silicone and consists of an inflatable 


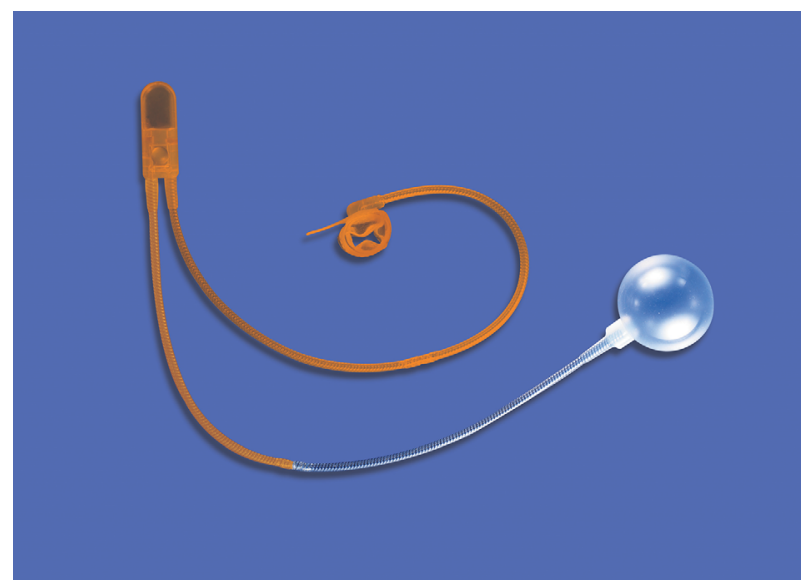

Figure I The AMS 800 (American Medical Systems, Minnetonka, MN, USA) artificial urinary sphincter developed in 1983, with the addition of the InhibiZone coating in 2007.

Note: Image courtesy of Boston Scientific Corporation.

narrow backed cuff, a pressure-regulating balloon (PRB), and a control unit that consists of a deflating pump, a refill resistor, and deactivating button. The AUS has not undergone any significant changes except for the addition of a $3.5 \mathrm{~cm}$ cuff introduced in $2009 .{ }^{6,7}$ After 4 decades of existence, there is substantial experience with the AUS. This article focuses on current perspectives regarding its use today.

\section{Device}

The AUS consists of three separate components whose tubing must be connected using connectors provided within the AMS accessory kit. The occlusive cuff ranges from $3.5 \mathrm{~cm}$ to $11 \mathrm{~cm}$ and most commonly is placed circumferentially at the bulbar urethra. The circumference of the urethra determines the cuff size. In certain situations, it is placed more distally as in transcorporal approaches. The cuff can even be placed at the bladder neck in rare instances, although this approach requires more extensive retropubic surgical dissection. The width of all cuff sizes when deflated is $2 \mathrm{~cm}$. AMS introduced the narrow backed cuff in $1987^{5,8}$ in an attempt to decrease the rates of reoperation. The cuff may be coated with InhibiZone (American Medical Systems), which was approved by the US Food and Drug Administration in 2007, although presently there are no data showing that InhibiZone reduces infection rates.

The PRB transmits pressure to the occlusive cuff and comes in six pressure ranges from $41 \mathrm{cmH}_{2} \mathrm{O}$ to $100 \mathrm{cmH}_{2} \mathrm{O}$ in increments of $10 \mathrm{cmH}_{2} \mathrm{O}$. The most commonly used PRB pressure range is $61-70 \mathrm{cmH}_{2} \mathrm{O}$. The goal of pressure regulation is to provide the lowest amount of pressure that is sufficient for continence. Excessive pressure will increase ischemia to the urethral segment being occluded and may lead to urethral atrophy and erosion. The PRB may be placed in the space of Retzius, in a submuscular location, ${ }^{9}$ or via a counter incision in a preperitoneal space. Some favor placement of the PRB in a high submuscular location, giving comparable functional outcomes in comparison to traditional placement within the space of Retzius, while avoiding associated complications of the latter and facilitating PRB placement in reoperative cases with a hostile abdomen. ${ }^{10}$

The final component is the control unit or pump and consists of two parts. The lower part is a bulb that the patient squeezes to transfer fluid out of the compressive cuff to the PRB allowing micturition. The upper part contains the resistor valves and deactivation button. In men, the pump is placed within a subdartos pouch within the scrotum where it can be easily accessed by the patient. Proper manipulation of the pump requires a certain degree of manual dexterity by the patient, which should be assessed preoperatively. ${ }^{11}$

\section{Indications}

The AUS is an effective treatment for intrinsic sphincter deficiency in men resulting from various etiologies, which may include prostate cancer treatment, transurethral resection of prostate, neurologic disease, trauma, or congenital anomalies. Prior to 1985, a significant proportion (17\%-50\%) of AUSs were placed for neurologic disease. ${ }^{12}$ However since 1985, postprostatectomy incontinence (PPI) has been the most common indication, representing 39\% to $69 \%$ of AUS placed through 2005.,12 Indications for spinal cord injury are relatively narrow as thoracolumbar spinal cord injuries resulting in intrinsic sphincter deficiency are relatively rare. Most AUSs placed for spinal cord disease are in the pediatric population with myelodysplasia. Women currently account for $<1 \%$ of AUS placements, ${ }^{13}$ and the AMS 800 is not US Food and Drug Administration approved for use in women. This review focuses on AUS as it is most commonly used today, in men with SUI. In the era of robotic-assisted radical prostatectomies, the incidence of 12-month urinary incontinence rates varies between $4 \%$ and $31 \% .{ }^{14}$ However, only a portion of these patients will undergo AUS placement. Currently, $\sim 11,500$ AUSs are placed annually worldwide. In 2005, only $13 \%$ of US urologists performed AUS surgery, with only $4 \%$ considered high-volume surgeons, performing $>20$ per year. ${ }^{12}$

Traditionally, a waiting period of at least 1 year following prostate cancer treatment prior to placing an AUS has been suggested. However, more recent expert opinion agrees that an AUS may be placed as early as 6 months following radical prostatectomy (RP), if SUI is severe, bothersome to the patient, and not improving with conservative treatment. ${ }^{11}$ On the other hand, if there is ongoing improvement in SUI 
even 12 months after RP it is up to the surgeon's discretion to delay surgical management of SUI. A cystoscopy prior to placement of an AUS is traditionally advised to look for any underlying urethral pathology that may complicate AUS placement or that may put the AUS at risk of subsequent damage. For example, up to $32 \%$ of patients have been found to have a vesicourethral anastomotic stricture on cystoscopy following RP. ${ }^{15}$ Vesicourethral anastomotic strictures should be stable prior to AUS placement.

\section{Outcomes}

There are more than 400 articles that have been published regarding outcomes of the AUS; however, most of the literature are retrospective series, with heterogeneous groups and different definitions regarding improvement or success making direct comparison of studies difficult. Success rates vary widely between $61 \%$ and $100 \%{ }^{16-22}$ In a recent systematic review, social continence ( $£ 1 \mathrm{pad} / \mathrm{d}$ ) was reported at $79 \%$ with follow-up ranging from 5 months to 192 months. ${ }^{23}$ Dry rates varied between $4 \%$ and $86 \%$. In a prospective study of 103 patients suffering from PPI, the dry rate was $57 \% .{ }^{21}$ Patients should be provided with realistic expectations, regarding their continence. They should be advised to expect an improvement in their continence, but not to be necessarily $100 \%$ dry. Many patients continue to wear a safety pad and are quite satisfied with such results. ${ }^{24}$ Litwiller et $\mathrm{al}^{25}$ found that patients with an AUS who leaked less than a teaspoon a day were satisfied and would recommend the surgery to a friend. Patients were more likely to be dissatisfied when they leaked more than a teaspoon per day. Generally, the AUS has good long-term outcomes and improves SUI sufficiently achieving a high patient satisfaction usually $80 \%-90 \% .^{17,25-27}$

A significant proportion of patients suffer from SUI following radical cystectomy with neobladder (RC/NB). Studies report the incidence of SUI after RC/NB to be between 33\% and $95 \% .^{28,29}$ Only few studies exist evaluating outcomes in patients with orthotopic neobladders who have undergone an AUS. In one of the largest series reported, ${ }^{30} 72 \%$ (21/29) of patients noted an improvement in SUI at a mean follow-up of 40 months. However, $60 \%$ of patients underwent a revision or explantation due to infection, erosion, device malfunction, or recurrent SUI, with erosion or infection being the most common reason. Most of the AUSs placed in this series were $4.5 \mathrm{~cm}$ cuffs with $61-70 \mathrm{~cm}$ balloons. Of these patients, $28 \%$ had been treated with radiotherapy. In comparison to PPI, these outcomes seem poorer. A small proportion of RC/NB patients perform clean intermittent catheterization. This is an additional important factor to consider prior to placing an
AUS as it may possibly increase the risk of erosion secondary to catheterization trauma.

\section{Complications}

Despite the good outcomes achieved with the AUS, it does come with a substantial need for revision surgery. A candid discussion on the potential complications of the procedure should be discussed with the patient including infection, urinary retention, urethral atrophy, erosion, or device malfunction. The complication rates are generally low; however, the need for revision surgery increases with time.

\section{Infection}

As with any foreign body, infection can be a significant concern and mandates early recognition and explantation. An infection usually presents with scrotal erythema and induration at the site of the pump. It is advised to remove all components when patients present with concerns for an infected AUS, given the possibility of biofilm formation along the device. ${ }^{11}$ The rate of infection in contemporary series are reported to be between $1 \%$ and $8 \%,{ }^{31-35}$ with rates $<2 \%$ at high volume centers. ${ }^{8,36,37}$ Gram-positive organisms such as Staphylococcus aureus and Staphylococcus epidermidis account for the majority of infections, with methicillin resistance reported in $26 \%$ of organisms. ${ }^{38}$ Gram-negative infections account for $26 \%$ of infections. ${ }^{38}$ Perioperative antibiotics are routinely administered; however, there is no standardized antibiotic regimen and the choice of antibiotics is dependent on surgeon preference. Our recommendation is to provide both grampositive and gram-negative coverage with consideration of coverage for methicillin-resistant Staphylococcus species. ${ }^{11}$

\section{Urinary retention}

A subset of patients suffer from urinary retention. This most often is transient and may be due to postoperative urethral inflammation, which should typically resolve over the course of several days. In a large series, Linder et $\mathrm{al}^{39}$ noted the rate of postoperative urinary retention to be $31 \%$. Prolonged catheterization with an AUS is not recommended given that it may lead to erosion by compromising blood flow to the urethra. The smallest caliber catheter available ought to be used if needed (eg, 10 Fr or 12 Fr) and if needed for $>48$ hours, a suprapubic tube should be considered. ${ }^{11,34}$ If urinary retention persists for longer than a week, improper cuff sizing may be the cause, and the patient may benefit from undergoing a revision with cuff upsizing. Interestingly, urinary retention was found to be associated with adverse 6-month device survival and increased rates of erosion. ${ }^{39}$ 


\section{Urethral atrophy}

Urethral tissue atrophy, which is among the most common complications following AUS implantation, may occur naturally following persistent cuff-induced urethral compression and ischemia. Urethral atrophy and erosion lie on a spectrum and are both most often secondary to the constant compression experienced by the urethra, erosion being the more severe complication. The urethra may lose tissue bulk circumferentially with time, and a cuff that was initially sized appropriately may become too large for adequate urethral coaptation. Patients who experience urethral atrophy often complain of recurrent incontinence as a late presentation. Use of narrow-backed cuffs was meant to provide persistent adequate coaptation as urethral tissue lost bulk over time, translating into a reduced revision rate. ${ }^{24}$ Once atrophy occurs, various revision strategies, discussed in detail later, may be used to manage recurrent incontinence, including but not limited to downsizing the cuff, repositioning the cuff preferably more proximal, transcorporal cuff placement, and tandem cuff placement. Increasing the cuff pressure is not recommended as this leads to further ischemia and possibly urethral erosion.

\section{Urethral erosion}

Erosions may occur as either an early or a late postoperative complication. When an erosion presents within the first few months, it is likely that there was an unrecognized intraoperative urethral injury at the time of AUS placement. ${ }^{34}$ Late erosions present at a median time of 19 months and at a rate of $5 \%-10 \% .{ }^{40}$ Over time constant cuff compression may cause urethral tissue atrophy and eventually erosion. Prior studies have shown that radiation-induced endarteritis, prior urethral surgery including urethroplasty and prior anti-incontinence surgery, coronary artery disease, and compromised urethral blood flow are all risk factors for erosion. ${ }^{41,42}$ Since both urethral atrophy and erosion may present with recurrent SUI, patients who present with a recurrence of symptoms should undergo a cystoscopy before undergoing any surgical intervention to rule out erosion as these two complications are managed differently. Eroded cuffs will be exposed to urine and are traditionally associated with infection. Some erosions, however, may not show signs of overt infection within the scrotum or perineum and may remain sterile for many years. These may go unnoticed for a long time. ${ }^{43}$

When a patient experiences an erosion, the device should be explanted. A recent study found that the incidence of urethral stricture formation was significantly lower when patients underwent an in situ urethroplasty, which reapproximated the epithelial edges (38\%), compared to patients treated solely with an indwelling Foley catheter (85\%). ${ }^{44}$ Furthermore, stricture development leads more intervening procedures prior to replacement of a new AUS, impacting a patient's quality of life by delaying the restoration of continence. In this series, the average interval before AUS replacement was 9 months for those who underwent an in situ urethroplasty vs 17 months for those who received Foley catheter drainage only. ${ }^{44} \mathrm{~A}$ new device may then be implanted after a 3-month healing period. Nocturnal deactivation has been suggested as a prevention strategy to avoid urethral atrophy and subsequent erosion. This may be a strategy to consider in motivated patients that have the manual dexterity and understanding of how the mechanism operates.

\section{Radiation}

It is worth mentioning that radiated patients may constitute a group of patients with an increased risk of complications. A significant proportion of patients with a history of locally advanced prostate cancer treatment undergo adjuvant radiotherapy. These patients should be advised that they might be at higher risk of needing revision surgery. Radiotherapy is associated with endarteritis and chronic vascular changes that may decrease urethral blood flow leading to spongiosal atrophy prior to AUS implantation. ${ }^{11}$ Several series have found higher rates of erosion or complications necessitating revisions in patients with a prior history of radiation. ${ }^{7,17,45,46}$ Despite these risks, AUS implantation leading to satisfactory continence has been successfully performed in irradiated patients. Some surgeons prefer transcorporal cuff placement in such instances and others have suggested using a lower pressured PRB (51-60 $\left.\mathrm{cmH}_{2} \mathrm{O}\right)$ and delayed activation at 6 weeks. ${ }^{43}$

\section{Mechanical failure}

If patients develop recurrent or worsening SUI and are not found to have an erosion, it may be that the device has failed. Mechanical failures on average occur later than urethral atrophy, erosions, and infections ${ }^{47}$ Imaging such as an ultrasound of the PRB or a CT scan may confirm a loss of fluid within the system. However, imaging will not help determine the exact location of the leak. It is advised that if there is a mechanical failure of the device after 2 years, the whole device should be replaced. Higher rates of mechanical failure were noted in a series of revisions where patients did not have complete replacements but merely had their cuffs downsized. ${ }^{48}$ Some have suggested that performing partial replacements of an AUS can lead to higher failure/leakage 
rates secondary to biofilm that builds on the in situ components if one uses the accessory quick connect kit rather than suture tie the connections. ${ }^{49}$

\section{Revisions}

Although the durability of AUS has been well established, a significant percentage of patients undergo revisions for various reasons, including, erosion, infection, urethral atrophy, and mechanical failure. The proportion of AUS revision surgeries performed annually is $\sim 24 \%-34 \%$. ${ }^{12}$ Generally, the reported revision rate is $\sim 25 \% .{ }^{47}$ However, it is important to consider long-term outcomes as device survival rate diminishes with longer follow-up. More specifically, reported 5 -year survival rates vary between $59 \%$ and $79 \%,{ }^{18,36,40,47,50,51}$ 10 -year survival rates between $28 \%$ and $64 \%,{ }^{47,50-52}$ and 15 -year survival rates between $15 \%$ and $41 \% .^{47,50}$ In the largest series of 1,082 AUS from a single institution with long follow-up of up to 15 -years, the device survival rate at 5 years, 10 years, and 15 years was $74 \%, 57 \%$, and $41 \%$, respectively. ${ }^{47}$ These numbers are quite significant, and based on these data, patients with a significant life expectancy (greater than a decade) have a high likelihood of needing to undergo a revision in their lifetime. Although there is a high revision rate with time, most series show that AUS revisions have comparable outcomes to initial AUS placement, ${ }^{36,53,54}$ particularly if undergoing a revision for mechanical failure. Patients undergoing revisions for multiple erosions have compromised urethras and may be at higher risk of subsequent erosions. ${ }^{42}$ Revision techniques include repositioning the cuff at a different location along the urethra (preferably more proximal if possible) and downsizing the cuff, using tandem cuffs or transcorporal cuffs. In the largest multiinstitutional series of revisions, the mean time to revision was 28.9 months. ${ }^{48}$ Additionally, patient satisfaction has been shown to be independent of the number of revisions, and studies have shown that up to $90 \%$ of patients undergoing revision had no change in satisfaction as long as they had a functional AUS. ${ }^{24-26}$

\section{Tandem cuffs}

In an effort to improve efficacy and continence, some have used tandem cuffs with the thought that increasing resistance over a greater area may improve continence. According to American Medical Systems, $\sim 15 \%$ of AUS are placed as tandem cuffs. ${ }^{55}$ Brito et al ${ }^{56}$ was the first to describe successful tandem cuff placement with success reported at 95\%. The idea behind tandem cuffs was that using two cuffs would lead to increased resistance to leakage ${ }^{57}$ without increasing pressure on a single segment of the urethra. Despite initial enthusiasm and favorable continence outcomes from several groups following tandem cuffs for patients with severe PPI, urethral atrophy or prior failed single cuff placement, ${ }^{56-60}$ subsequent longer follow-up demonstrated a higher risk of complications when using tandem cuffs. ${ }^{18}$ Additionally, the authors of a cadaver study did not find a significant difference in retrograde leak point pressure for single vs tandem cuffs. They did find an association between urethral circumference and retrograde leak point pressure, which favors proximal cuff placement. ${ }^{61}$ In reviewing this literature, one must keep in mind that most of these series ${ }^{56,57,59,60,62}$ are retrospective in nature and not randomized. Therefore, a selection bias in choosing patients who underwent tandem cuff placement likely exists. It is likely that two cuffs do provide greater continence, but the benefit may be not worth the cost of increased complications.

\section{Transcorporal}

Transcorporal cuff placement was developed in an attempt to improve continence in patients with recurrent incontinence secondary to erosion, subcuff urethral atrophy, inadequate urethral coaptation, or for patients undergoing revisions where more proximal placement could not be achieved. ${ }^{63}$ Initial success for transcorporal placement was reported at $84 \%$. The advantages of transcorporal placement include avoiding a difficult distal dorsal urethral dissection near the corpora, which may result in a thin urethra, as well as the additional bulk provided by the tunica. In a prospective series of transcorporal AUS placement, dry or socially continent rates were reported to be $76 \%$ at median follow-up of 20 months. ${ }^{64}$

There is a concern that transcorporal cuff placement affects erectile dysfunction. However, most patients undergoing transcorporal cuff placement have undergone prostate cancer treatment and already have some degree of erectile dysfunction at baseline. ${ }^{20,64-67}$ Despite this concern, a small series did report that the majority of patients maintain their erectile function even after transcorporal cuff placement if they had it to begin with, although the numbers are small, $5 / 6(83 \%){ }^{64}$

\section{AUS following sling placement}

The outcomes of primary AUS placement are comparable to those performed after prior sling placement. Following sling surgery, recurrence of incontinence ranges from $20 \%$ to $35 \% .{ }^{68}$ An AUS may be placed following a bone-anchored sling, transobturator sling, or quadratic sling. Transobturator 
slings may be left in place when placing the AUS. Usually, the transobturator sling cannot be seen during the AUS placement, and the AUS may simply be placed around the bulbar urethra via a perineal incision. In order to place an AUS after a bone-anchored sling, the sling must be incised and dissected off the bulbospongiosus muscle to expose the bulbar urethra or the AUS may be placed more distally via a transscrotal approach. ${ }^{69}$ Finally, the quadratic sling can easily be identified through the perineum and can be incised and dissected from the bulbospongiosus muscle unveiling the unscarred urethra deep to it and allowing placement of the AUS. ${ }^{68}$ AUS outcomes following sling placement are high, with success rates reported to be $79 \%-83 \% .^{70,71}$ Complication rates appear to be similar to initial AUS placement.

\section{New inventions}

Despite an increase in surgical options for PPI, including slings, bulking agents, and stem cell therapy, the AUS remains the gold standard. Given the difficulties with implanting the device, as well as the significant rate for revisions, there has been a push for the development of new devices. In recent years, there have been new inventions; however, none have yet been approved for use in the US. Most of these new devices attempt to simplify implantation by decreasing the number of connecting parts. Additionally, many of these devices are developed to allow in situ adjustment of the pressure cuff since constant urethral pressure is the likely cause of urethral atrophy and subsequent erosion.

\section{FlowSecure}

An adjustable AUS named the FlowSecure (Sphinx Medical, Bellshill, Scotland) has been undergoing trials predominately in the UK. Developed in 2006, it functions similarly to the AUS in that it has a PRB, pump, and cuff; however, the FlowSecure has an additional "stress-relieving balloon" and comes as a one-piece device. ${ }^{72,73}$ The idea of the FlowSecure is to decrease the magnitude of constant urethral pressure in the hope that this will decrease the erosion rates. It has two separate balloons, one that keeps the cuff inflated at low pressures and another which increases pressure to the cuff in response to an increase in intra-abdominal pressure. ${ }^{74}$ The "stress relieving balloon" allows the cuff to rest at a lower baseline pressure exerted by the PRB by providing intermittent increases in pressure to the urethra that is administered when there is an increase in intra-abdominal pressure. Additionally, the pressure of the FlowSecure can be adjusted by injecting or removing saline transscrotally through the pump, allowing individualization of the pressure according to the individual patient's SUI severity. Although initial results in nine patients appeared promising, ${ }^{72}$ in another study of 100 patients who underwent placement of the FlowSecure, 28\% underwent explantation of the device for early and late infections, perforation of the pump at pressurization and mechanical failure. ${ }^{75}$ An additional disadvantage is that patients require multiple pressurization procedures, typically three before reaching an adequate pressure. ${ }^{73}$

\section{Periurethral constrictor}

The periurethral constrictor (PUC; Silimed, Rio de Janeiro, Brazil) was initially designed in 1996 for pediatric patients. However, its use has been reported in adults with PPI. The PUC is an adjustable hydraulic system that includes the constrictor connected to a valve that is placed subcutaneously in the lower abdomen where it can be accessed and punctured with a needle. Patients do not need to mechanically pump the PUC and typically must void abdominally. Although initial reports were not as robust, ${ }^{76}$ the most recent report of 62 patients with at least 18-month follow-up indicates a continence rate of $79 \% .{ }^{77}$

\section{Zephyr}

The Zephyr or ZSI 375 is an AUS produced by Zephyr Surgical Implants (Geneva, Switzerland), a Swiss-French company. It is a hydraulic-based system that is implanted as a single unit via two separate incisions. The cuff is placed via a perineal incision, and the pump is placed in a subdartos pouch within the scrotum. The pump is adjustable in situ so that urethral pressure may be adjusted as needed to improve continence. In a series of 34 patients with SUI, "social continence" was achieved in $94.2 \%$. Two devices (5.8\%) were explanted because of infection. Longer follow-up is needed to determine the durability of the device and the rates of explantation due to urethral atrophy or erosion. ${ }^{78}$

\section{Tape mechanical occlusive device}

A new artificial sphincter, the Tape Mechanical Occlusive Device (TMOD; GT Urological, Minneapolis, MN, USA) is currently under development. ${ }^{79}$ Rather than rely on a hydraulic mechanism such as the AMS 800, TMOD uses a springloaded mechanism to apply circumferential pressure around the urethra. This device is also a one-piece device that should facilitate implantation. The control is an ON and OFF switch, which patients should find easier to control than the pump of the current AMS 800. At this time, the TMOD has only been studied in a canine model and human cadavers. These studies have demonstrated that the device provides occlusive 
pressure when activated in the $50-80 \mathrm{cmH}_{2} \mathrm{O}$ range. Thus, far it has proven to be technically feasible and biocompatible. Live human clinical trials are to follow.

Various new devices are under development. None are currently approved for use in the US. Most of the devices at this time require further investigation, need to be implanted in a greater number of patients, and need longer follow-up to determine their durability and long-term rates of complications. An advantage of most of the new devices is that they are purportedly less expensive than the AMS 800 .

\section{Conclusion}

Despite the wide variation in results and heterogeneity of studies, one can surmise that the AUS has been a highly effective surgical solution for many patients suffering from moderate to severe SUI and has significantly improved the quality of life for many patients. However, given the current mechanism inherent to the function of the AUS which is via urethral compression, concerns for urethral atrophy and erosion arise from potentially decreased perfusion of the affected urethral segment. Additionally, with time, mechanical failure of the device may occur. Therefore, a significant percentage of patients will require a revision, which increases with longer follow-up. Various techniques and strategies have been developed over the years to successfully handle these clinical scenarios. While we continue to await the outcomes of newer devices under development, the AMS 800 model currently remains the gold standard.

\section{Disclosure}

The authors report no conflicts of interest in this work.

\section{References}

1. Landefeld CS, Bowers BJ, Feld AD, et al. National Institutes of Health state-of-the-science conference statement: prevention of fecal and urinary incontinence in adults. Ann Intern Med. 2008;148(6): 449-458.

2. Markland AD, Goode PS, Redden DT, Borrud LG, Burgio KL. Prevalence of urinary incontinence in men: results from the national health and nutrition examination survey. J Urol. 2010;184(3):1022-1027.

3. Foley FE. An artificial sphincter; a new device and operation for control of enuresis and urinary incontinence. J Urol. 1947;58(4): 250-259.

4. Leibovich BC, Barrett DM. Use of the artificial urinary sphincter in men and women. World J Urol. 1997;15(5):316-319.

5. Light JK, Reynolds JC. Impact of the new cuff design on reliability of the AS800 artificial urinary sphincter. J Urol. 1992;147(3): 609-611.

6. Hudak SJ, Morey AF. Impact of $3.5 \mathrm{~cm}$ artificial urinary sphincter cuff on primary and revision surgery for male stress urinary incontinence. J Urol. 2011;186(5):1962-1966.

7. Simhan J, Morey AF, Singla N, et al. $3.5 \mathrm{~cm}$ artificial urinary sphincter cuff erosion occurs predominantly in irradiated patients. J Urol. 2015; 193(2):593-597.
8. Elliott DS, Barrett DM. Mayo Clinic long-term analysis of the functional durability of the AMS 800 artificial urinary sphincter: a review of 323 cases. J Urol. 1998;159(4):1206-1208.

9. Morey AF, Cefalu CA, Hudak SJ. High submuscular placement of urologic prosthetic balloons and reservoirs via transscrotal approach. $J$ Sex Med. 2013;10(2):603-610.

10. Singla N, Siegel JA, Simhan J, et al. Does pressure regulating balloon location make a difference in functional outcomes of artificial urinary sphincter? J Urol. 2015;194(1):202-206.

11. Biardeau X, Aharony S, AUS Consensus Group, Campeau L, Corcos J. Artificial urinary sphincter: report of the 2015 consensus conference. Neurourol Urodyn. 2016;35(suppl 2):S8-S24.

12. Lee R, TeAE, Kaplan SA, Sandhu JS. Temporal trends in adoption of and indications for the artificial urinary sphincter. J Urol. 2009;181(6):2622-2627.

13. Ficarra V, Novara G, Rosen RC, et al. Systematic review and metaanalysis of studies reporting urinary continence recovery after robotassisted radical prostatectomy. Eur Urol. 2012;62(3):405-417.

14. Crivellaro S, Morlacco A, Bodo G, et al. Systematic review of surgical treatment of post radical prostatectomy stress urinary incontinence. Neurourol Urodyn. Epub 2015 Sep 23.

15. Comiter CV, Dobberfuhl AD. The artificial urinary sphincter and male sling for postprostatectomy incontinence: which patient should get which procedure? Investig Clin Urol. 2016;57(1):3-13.

16. Ramsay AK, Granitsiotis P, Conn IG. The use of the artificial urinary sphincter in the West of Scotland: a single centre 10-year experience. Scott Med J. 2007;52(2):14-17.

17. Walsh IK, Williams SG, Mahendra V, Nambirajan T, Stone AR. Artificial urinary sphincter implantation in the irradiated patient: safety, efficacy and satisfaction. BJU Int. 2002;89(4):364-368.

18. O'Connor RC, Lyon MB, Guralnick ML, Bales GT. Long-term followup of single versus double cuff artificial urinary sphincter insertion for the treatment of severe postprostatectomy stress urinary incontinence. Urology. 2008;71(1):90-93.

19. Imamoglu MA, Tuygun C, Bakirtas H, Yigitbasi O, Kiper A. The comparison of artificial urinary sphincter implantation and endourethral macroplastique injection for the treatment of postprostatectomy incontinence. Eur Urol. 2005;47(2):209-213.

20. Aaronson DS, Elliott SP, McAninch JW. Transcorporal artificial urinary sphincter placement for incontinence in high-risk patients after treatment of prostate cancer. Urology. 2008;72(4):825-827.

21. Mottet N, Boyer C, Chartier-Kastler E, Ben Naoum K, Richard F, Costa P. Artificial urinary sphincter AMS 800 for urinary incontinence after radical prostatectomy: the French experience. Urol Int. 1998;60(suppl 2): 25-29. [discussion 35].

22. O'Connor RC, Nanigian DK, Patel BN, Guralnick ML, Ellision LM, Stone AR. Artificial urinary sphincter placement in elderly men. Urology. 2007;69(1):126-128.

23. Van der Aa F, Drake MJ, Kasyan GR, Petrolekas A, Cornu JN; Young Academic Urologists Functional Urology Group. The artificial urinary sphincter after a quarter of a century: a critical systematic review of its use in male non-neurogenic incontinence. Eur Urol. 2013;63(4):681-689.

24. Gousse AE, Madjar S, Lambert MM, Fishman IJ. Artificial urinary sphincter for post-radical prostatectomy urinary incontinence: long-term subjective results. J Urol. 2001;166(5):1755-1758.

25. Litwiller SE, Kim KB, Fone PD, White RW, Stone AR. Post-prostatectomy incontinence and the artificial urinary sphincter: a long-term study of patient satisfaction and criteria for success. J Urol. 1996; 156(6):1975-1980.

26. Montague DK. Artificial urinary sphincter: long-term results and patient satisfaction. Adv Urol. 2012;2012:835290.

27. Montague DK, Angermeier KW, Paolone DR. Long-term continence and patient satisfaction after artificial sphincter implantation for urinary incontinence after prostatectomy. J Urol. 2001;166(2):547-549.

28. Santucci RA, Park CH, Mayo ME, Lange PH. Continence and urodynamic parameters of continent urinary reservoirs: comparison of gastric, ileal, ileocolic, right colon, and sigmoid segments. Urology. 1999; 54(2):252-257. 
29. Hautmann RE, de Petriconi R, Gottfried HW, Kleinschmidt K, Mattes R, Paiss T. The ileal neobladder: complications and functional results in 363 patients after 11 years of followup. J Urol. 1999;161(2):422-427. [discussion 427-428].

30. Vainrib M, Simma-Chiang V, Boyd SD, Ginsberg DA. Potential risk factors and outcomes of artificial urinary sphincter placement after radical cystectomy and orthotopic neobladder urinary diversion. Neurourol Urodyn. 2013;32(7):1010-1013.

31. de Cogain MR, Elliott DS. The impact of an antibiotic coating on the artificial urinary sphincter infection rate. J Urol. 2013;190(1): 113-117.

32. Bordenave $\mathrm{M}$, Roupret $\mathrm{M}$, Taksin $\mathrm{L}$, et al. Résultats à long terme du traitement de l'incontinence urinaire masculine par implantation de sphincter artificiel urinaire (AMS 800) en position bulbaire: expérience monocentrique [Long-term results of the treatment of urinary incontinence with bulbar implantation of artificial urinary sphincter in men: a single-center experience]. Prog Urol. 2011;21(4):277-282. French.

33. Montague DK, Angermeier KW. Postprostatectomy urinary incontinence: the case for artificial urinary sphincter implantation. Urology. 2000;55(1): $2-4$.

34. Suarez OA, McCammon KA. The artificial urinary sphincter in the management of incontinence. Urology. 2016;92:14-19.

35. Hajivassiliou CA. A review of the complications and results of implantation of the AMS artificial urinary sphincter. Eur Urol. 1999;35(1): $36-44$.

36. Raj GV, Peterson AC, Toh KL, Webster GD. Outcomes following revisions and secondary implantation of the artificial urinary sphincter. J Urol. 2005;173(4):1242-1245.

37. Raj GV, Peterson AC, Webster GD. Outcomes following erosions of the artificial urinary sphincter. J Urol. 2006;175(6):2186-2190. [discussion 2190].

38. Magera JS Jr, Elliott DS. Artificial urinary sphincter infection: causative organisms in a contemporary series. J Urol. 2008;180(6):2475-2478.

39. LinderBJ,PiotrowskiJT,Ziegelmann MJ, Rivera ME, Rangel LJ,ElliottDS. Perioperative complications following artificial urinary sphincter placement. J Urol. 2015;194(3):716-720.

40. Lai HH, Hsu EI, Teh BS, Butler EB, Boone TB. 13 years of experience with artificial urinary sphincter implantation at Baylor College of Medicine. J Urol. 2007;177(3):1021-1025.

41. Brant WO, Erickson BA, Elliott SP, et al. Risk factors for erosion of artificial urinary sphincters: a multicenter prospective study. Urology. 2014;84(4):934-938.

42. McGeady JB, McAninch JW, Truesdale MD, Blaschko SD, Kenfield S, Breyer BN. Artificial urinary sphincter placement in compromised urethras and survival: a comparison of virgin, radiated and reoperative cases. J Urol. 2014;192(6):1756-1761.

43. Singla N, Singla AK. Review of single-surgeon 10-year experience with artificial urinary sphincter with report of sterile cuff erosion managed nonsurgically. Urology. 2015;85(1):252-256.

44. Rozanski AT, Tausch TJ, Ramirez D, Simhan J, Scott JF, Morey AF. Immediate urethral repair during explantation prevents stricture formation after artificial urinary sphincter cuff erosion. $J$ Urol. 2014;192(2): 442-446.

45. Bates AS, Martin RM, Terry TR. Complications following artificial urinary sphincter placement after radical prostatectomy and radiotherapy: a meta-analysis. BJU Int. 2015;116(4):623-633.

46. Ravier E, Fassi-Fehri H, Crouzet S, Gelet A, Abid N, Martin X. Complications after artificial urinary sphincter implantation in patients with or without prior radiotherapy. BJU Int. 2015;115(2):300-307.

47. Linder BJ, Rivera ME, Ziegelmann MJ, Elliott DS. Long-term outcomes following artificial urinary sphincter placement: an analysis of 1082 cases at mayo clinic. Urology. 2015;86(3):602-607.

48. Eswara JR, Chan R, Vetter JM, Lai HH, Boone TB, Brandes SB. Revision techniques after artificial urinary sphincter failure in men: results from a multicenter study. Urology. 2015;86(1):176-180.

49. Kavoussi L, Novick AC, Partin AW, Peters CA. Campbell-Walsh Urology. 10th ed. Philadelphia, PA: Elsevier Saunders; 2011.
50. Leon P, Chartier-Kastler E, Roupret M, Ambrogi V, Mozer P, Phe V. Longterm functional outcomes after artificial urinary sphincter implantation in men with stress urinary incontinence. BJU Int. 2015;115(6):951-957.

51. Venn SN, Greenwell TJ, Mundy AR. The long-term outcome of artificial urinary sphincters. J Urol. 2000;164(3 pt 1):702-706. [discussion 706-707].

52. Kim SP, Sarmast Z, Daignault S, Faerber GJ, McGuire EJ, Latini JM. Long-term durability and functional outcomes among patients with artificial urinary sphincters: a 10 -year retrospective review from the University of Michigan. J Urol. 2008;179(5):1912-1916.

53. Lai HH, Boone TB. Complex artificial urinary sphincter revision and reimplantation cases - how do they fare compared to virgin cases? J Urol. 2012;187(3):951-955.

54. Linder BJ, de Cogain M, Elliott DS. Long-term device outcomes of artificial urinary sphincter reimplantation following prior explantation for erosion or infection. J Urol. 2014;191(3):734-738.

55. Chertack N, Chaparala H, Angermeier KW, Montague DK, Wood HM. Foley or fix: a comparative analysis of reparative procedures at the time of explantation of artificial urinary sphincter for cuff erosion. Urology. 2016;90:173-178.

56. Brito CG, Mulcahy JJ, Mitchell ME, Adams MC. Use of a double cuff AMS800 urinary sphincter for severe stress incontinence. J Urol. 1993; 149(2):283-285.

57. Kabalin JN. Addition of a second urethral cuff to enhance performance of the artificial urinary sphincter. J Urol. 1996;156(4):1302-1304.

58. Kowalczyk JJ, Spicer DL, Mulcahy JJ. Erosion rate of the double cuff AMS800 artificial urinary sphincter: long-term followup. J Urol. 1996; 156(4):1300-1301.

59. DiMarco DS, Elliott DS. Tandem cuff artificial urinary sphincter as a salvage procedure following failed primary sphincter placement for the treatment of post-prostatectomy incontinence. J Urol. 2003;170(4 pt 1): $1252-1254$

60. O'Connor RC, Gerber GS, Avila D, Chen AA, Bales GT. Comparison of outcomes after single or DOUBLE-CUFF artificial urinary sphincter insertion. Urology. 2003;62(4):723-726.

61. Manka MG, Wright EJ. Does use of a second cuff improve artificial urinary sphincter effectiveness? Evaluation using a comparative cadaver model. J Urol. 2015;194(6):1688-1691.

62. Kowalczyk JJ, Spicer DL, Mulcahy JJ. Long-term experience with the double-cuff AMS 800 artificial urinary sphincter. Urology. 1996;47(6): 895-897.

63. Guralnick ML, Miller E, Toh KL, Webster GD. Transcorporal artificial urinary sphincter cuff placement in cases requiring revision for erosion and urethral atrophy. J Urol. 2002;167(5):2075-2078. [discussion 2079].

64. Wiedemann L, Cornu JN, Haab E, et al. Transcorporal artificial urinary sphincter implantation as a salvage surgical procedure for challenging cases of male stress urinary incontinence: surgical technique and functional outcomes in a contemporary series. BJU Int. 2013;112(8):1163-1168.

65. Blah M, Caremel R, Sibert L, Bugel H, Grise P. Traitement de l'incontinence urinaire masculine par sphincter urinaire artificiel avec manchette intracaverneuse [Treatment of male urinary incontinence by artificial urinary sphincter with intracavernous cuff]. Prog Urol. 2008;18(2):114-119. French.

66. Lee D, Zafirakis H, Shapiro A, Westney OL. Intermediate outcomes after transcorporal placement of an artificial urinary sphincter. Int $J$ Urol. 2012;19(9):861-866.

67. Magera JS Jr, Elliott DS. Tandem transcorporal artificial urinary sphincter cuff salvage technique: surgical description and results. JUrol. 2007;177(3):1015-1019. [discussion 1019-1020].

68. Comiter C. Surgery for postprostatectomy incontinence: which procedure for which patient? Nat Rev Urol. 2015;12(2):91-99.

69. Comiter CV. Surgery insight: surgical management of postprostatectomy incontinence - the artificial urinary sphincter and male sling. Nat Clin Pract Urol. 2007;4(11):615-624.

70. Christine B, Knoll LD. Treatment of recurrent urinary incontinence after artificial urinary sphincter placement using the AdVance male sling. Urology. 2010;76(6):1321-1324. 
71. Abdou A, Cornu JN, Sebe P, et al. Thérapie de sauvetage par implantation d'un sphincter artificiel urinaire après échec de bandelette Advance $^{\mathrm{TM}}$ pour incontinence urinaire après prostatectomie: une expérience monocentrique [Salvage therapy with artificial urinary sphincter after advance male sling failure for post-prostatectomy incontinence: a first clinical experience]. Prog Urol. 2012;22(11):650-656. French.

72. Knight SL, Susser J, Greenwell T, Mundy AR, Craggs MD. A new artificial urinary sphincter with conditional occlusion for stress urinary incontinence: preliminary clinical results. Eur Urol. 2006;50(3): 574-580.

73. Vakalopoulos I, Kampantais S, Laskaridis L, Chachopoulos V, Koptsis M, Toutziaris C. New artificial urinary sphincter devices in the treatment of male iatrogenic incontinence. Adv Urol. 2012;2012:439372.

74. Craggs MD, Chaffey NJ, Mundy AR. A preliminary report on a new hydraulic sphincter for controlling urinary incontinence. J Med Eng Technol. 1991;15(2):58-62.
75. Rodriguez DA, Ascanio EF, Vicens VA, Garcia-Montes F. Four years experience with the FlowSecure Artificial Urinary Sphincter. Problems and Solutions. In: Proceedings of the 41st Annual Meeting of the International Continence Society (ICS ‘11); Glasgow, UK; August 2011.

76. Schiavini JL, Damiao R, de Resende Junior JA, Dornas MC, Cruz Lima da Costa DS, Barros CB. Treatment of post-prostate surgery urinary incontinence with the periurethral constrictor: a retrospective analysis. Urology. 2010;75(6):1488-1492.

77. Introini $\mathrm{C}$, Naselli A, Zaninetta $\mathrm{G}$, et al. Safety and efficacy of periurethral constrictor implantation for the treatment of post-radical prostatectomy incontinence. Urology. 2012;79(5):1175-1178.

78. Staerman F, G-Llorens C, Leon P, Leclerc Y. ZSI 375 artificial urinary sphincter for male urinary incontinence: a preliminary study. BJU Int. 2013;111(4 pt B):E202-E206.

79. Malaeb BS, Elliott SP, Lee J, Anderson DW, Timm GW. Novel artificial urinary sphincter in the canine model: the tape mechanical occlusive device. Urology. 2011;77(1):211-216.
Medical Devices: Evidence and Research

\section{Publish your work in this journal}

Medical Devices: Evidence and Research is an international, peerreviewed, open access journal that focuses on the evidence, technology, research, and expert opinion supporting the use and application of medical devices in the diagnosis, monitoring, treatment and management of clinical conditions and physiological processes. The identification of novel

\section{Dovepress}

devices and optimal use of existing devices which will lead to improved clinical outcomes and more effective patient management and safety is a key feature. The manuscript management system is completely online and includes a quick and fair peer-review system. Visit http://www. dovepress.com/testimonials.php to read real quotes from authors. 